\title{
Design of an Antenna for Mobile Satellite Services
}

\author{
R. Brinda ${ }^{1}$, E. Nisha Flora Boby ${ }^{2}$ \\ ${ }^{1}$ Assistant Professor, Department of Electronics and Communication Engineering, Mepco Schlenk Engineering College, Sivakasi 626005 \\ ${ }^{2}$ PG Student, Department of Electronics and Communication Engineering, Mepco Schlenk Engineering College, Sivakasi 626005
}

\begin{abstract}
In this paper, a miniaturized S-Band antenna for Mobile Satellite Services (MSS) with near Omni-directional coverage is designed for Mobile hand-held Terminals. Mobile Satellite Services is used for communication services between Mobile Earth Stations (MES) and space station during several disasters such as flood, hurricanes and earthquake. Four Hexagonal patch antenna surrounded by a square ring with a superstrate structure is designed to operate in dual frequency range with a single feed. The proposed antenna has $V$ - shaped slots to tune the antenna for achieving both uplink and downlink frequencies. The Slotted Hexagonal patch antenna resonate at centre frequency $1.99 \mathrm{GHz}$ and $2.18 \mathrm{GHz}$. The simulation has been performed by using Ansys HFSS, which is a Finite Element Method (FEM) based Electromagnetic Solver. A low cost and readily available FR-4 substrate of relative permittivity of 4.4 and height $3.2 \mathrm{~mm}$ has been used and fed with $50 \Omega$ microstrip line.
\end{abstract}

Keywords: Omni- directional coverage, Hexagonal patch, superstrate, dual frequency, Ansys HFSS.

\section{Introduction}

The next step for personal wireless communication systems is the mobile satellite communication which provides coverage over worldwide. One of the challenges for antenna engineers is to design a miniaturized antenna to deliver acceptable electrical performance for the mobile terminals. Mobile Satellite Services (MSS) is a services provided by a satellite system which helps for the communication service with portable terminals on the ground. The terminals can be carried by a person or mounted on a ship or car. The Mobile Satellite Services schematic diagram is given in Figure 1.

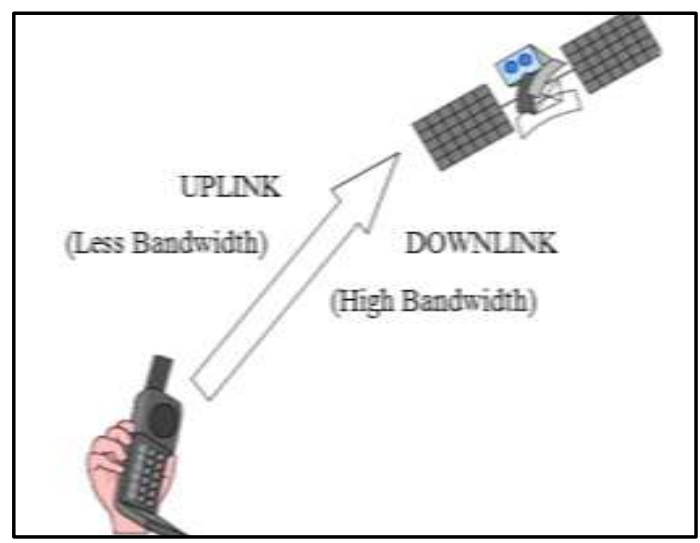

Figure 1: MSS uplink and downlink

Antenna in the handset must be located in clear line of sight for direct satellite. L- Band and S-band frequencies of radio spectrum are allocated for MSS services. Two multi-system antennas designed for the new European S-band mobile satellite systems. This design is installed on vehicles. The radiating element consists of four symmetrically arranged L-shaped monopoles above a round metallic ground plane. The dimension of proposed antenna is $140 \times 110 \mathrm{~mm}$ [1]. A low profile, light weight, and low cost antenna for dual-band operation in Ku-band for satellite applications are designed. The proposed structure consists of five slots in total, out of which slot 1 is circular with a Rectangular tail and all other remaining slots are rectangular in shape. Micro strip feed is used [2].The operating frequency ranges of the S-band Mobile Satellite Services are $1.98 \mathrm{GHz}-2.01 \mathrm{GHz}$ and $2.17 \mathrm{GHz}-2.2 \mathrm{GHz}$ for uplink and downlink frequencies respectively [3]. For satellite application in Ku-band, such as slot loaded patch with coaxial feed [4], E-shaped patch antenna [5]. A wide band Ku-band antenna is realized and simulated using ADS (Advance Design Systems) simulation tool. The wideband operation is using slitting and slotting techniques in Microstrip feed slotted antenna [6]. Some of the designs use coaxial feed in which one has to drill a hole in the substrate. In the survey, the antenna designed for MSS frequency range provides bidirectional coverage, large size. Achieving small size antenna for multiband application is very complex job. This motivates us to design a miniaturized slotted patch antenna with microstrip feed that meets the dual band requirements along with near Omni directional coverage and to be fit in mobile hand-held terminals.

\section{Design Formulae}

The width $(\mathrm{W})$ of the micro strip patch antenna is calculated using,

$$
W=\frac{C}{2 f_{r} \sqrt{\frac{\left(\varepsilon_{r}+1\right)}{2}}}
$$

where,

$C=$ Free space velocity of light.

$f_{r}=$ Frequency of operation

$\varepsilon_{r}=$ Dielectric constant

Effective length ( $\left.L_{e f f}\right)$ of the antenna is calculated by,

$$
L_{\theta f}=\frac{c}{2 f, \sqrt{\varepsilon_{n g f}}}
$$

Where,

$\varepsilon_{\text {reff }}=$ Effective dielectric.

\section{Volume 6 Issue 12, December 2017}




\section{International Journal of Science and Research (IJSR) \\ ISSN (Online): 2319-7064 \\ Index Copernicus Value (2016): 79.57 | Impact Factor (2015): 6.391}

Then effective dielectric constant is calculated as where,

$\varepsilon_{\text {reff }}=\frac{\varepsilon_{r}+1}{2}+\frac{\varepsilon_{r}-1}{2}\left[1+12 \frac{h}{w}\right]^{\frac{-1}{2}}$

$h=$ height of dielectric substrate.

$w=$ width of the patch.

The patch length extension is calculated by,

$$
\Delta L=0.412 h \frac{\left(\varepsilon_{\text {nof }}+0.3\right)\left(\frac{w}{h}+0.264\right)}{\left(\varepsilon_{\text {neff }}-0.258\right)\left(\frac{w}{h}+0.8\right)}
$$

Then the actual length of the patch is calculated by,

$$
L=L_{e f f}-2 \Delta L
$$

The Length of the ground plane is given by,

$$
L_{g}=L+6 h+6 h
$$

The Width of the ground plane is given by,

$$
W_{g}=W+6 h+6 h
$$

The effective radius of circular microstrip antenna is given by,

$$
a_{e}=a\left\{1-\frac{2 h}{\pi a \varepsilon_{T}}\left(\ln \frac{\pi a}{2 h}+1.7726\right)\right\}^{1 / 2}
$$

The relationship between the equivalent areas of circular and hexagonal patches in given as,

$$
\pi a_{\theta}^{2}=\frac{3 \sqrt{3}}{2} S^{2}
$$

By using the formula from equation (2.1) - (2.9) dimension for the antenna were calculated [7]. The calculated dimensions of the antenna are given in the table below.

\section{Antenna Design}

The proposed antenna is designed using low cost FR-4 substrate of $3.2 \mathrm{~mm}$ thickness. The antenna structure is shown in Figure 2. From the figure, the pink color shows the patch area and brown color is the substrate. Various design parameters used in simulation are given in Table 1. Initially the proposed structure consists of basic square ring microstrip antenna. The size of square patch is $47 * 47 \mathrm{~mm}$ designed for $1.99 \mathrm{GHz}$. In the proposed structure dimensions are $L=$ Length of the substrate, $\mathrm{W}=$ Width of the substrate, $L_{o}=$ Length of outer square ring patch, $W_{o}=$ Width of the outer square ring patch, $L_{i}=$ Length of inner square ring patch, $W_{i}=$ Width of inner square ring patch, $L_{f}=$ Length of the feed, $W_{f}=$ Width of the feed, $r=$ radius of the circle. The purpose of the ground plane is to overcome the spurious radiation of the particularly long microstrip transmission line in order to concentrate the radiation of the $\mathrm{E}$ and $\mathrm{H}$ fields onto the patch. Then four equal hexagonal patches are designed to achieve the downlink centre frequency $2.18 \mathrm{GHz}$. Microstrip line is used for feeding to meet the standard $50 \Omega$ impedance characteristics. The four hexagonal patches are united by Boolean operation and they meet at the circular patch at the centre. Hexagonal patches are united with the circle and results in four triangular shaped slots. These united patches are united with the square ring. Then four equal Vshaped slots are made in each hexagonal patch. This slot is used to tune the antenna to achieve both uplink and downlink frequencies. Slot 1 and slot 3 are used to tune the uplink frequency whereas slot 2 and slot 4 are used to tune the downlink frequency. Two layered superstrate structure is directly loaded on the patch using FR-4 material. This superstrate structure is used to alter the resonant frequency. The side view of superstrate layers is shown in Figure 3. Based on the current distribution, two strips are united on either side of the square ring.

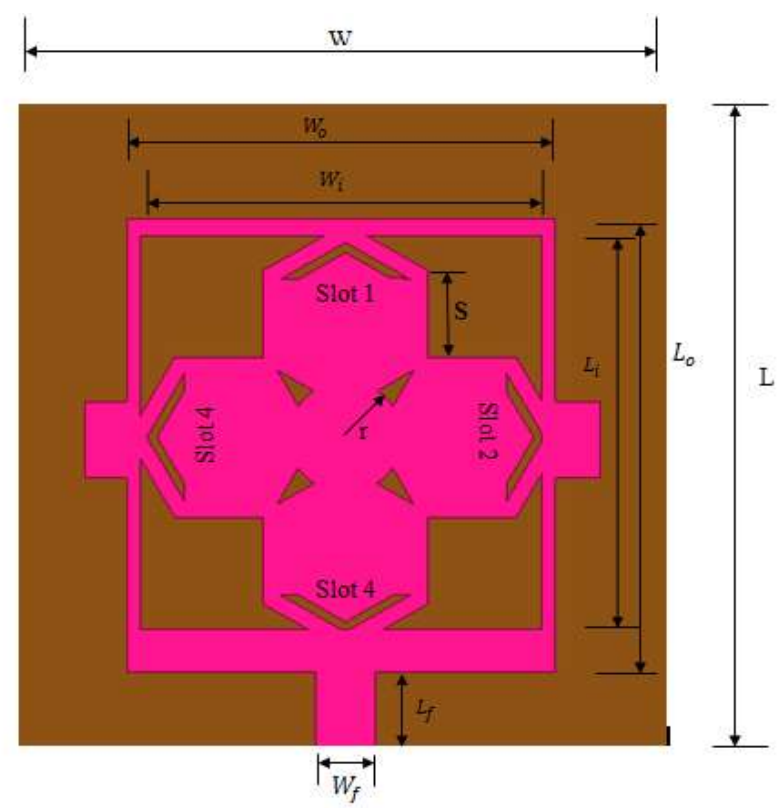

Figure 2: Proposed antenna structure

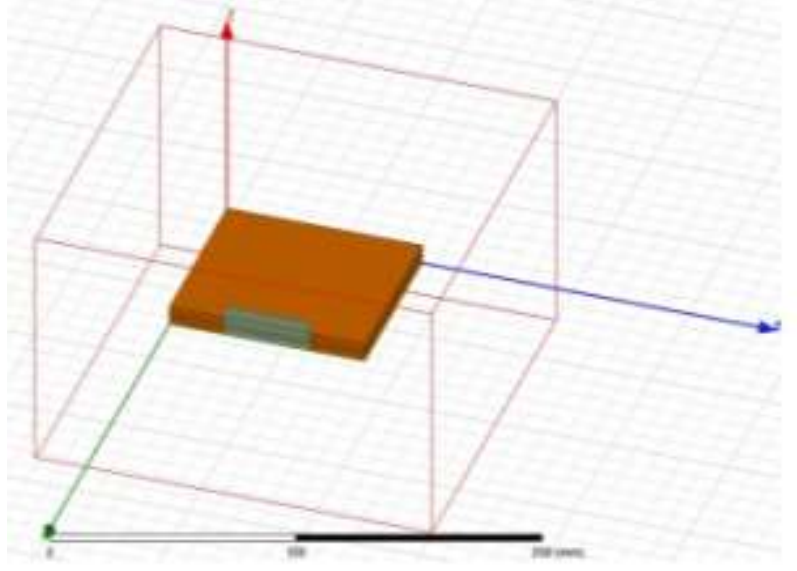

Figure 3: Side view of Superstrate layers over the patch

Table 1: Design Specifications of Microstrip Patch Antenna

\begin{tabular}{|l|l|}
\hline \multicolumn{1}{|c|}{ Description } & \multicolumn{1}{|c|}{ Dimension } \\
\hline Length of outer square ring patch $\left(L_{o}\right)$ & $47 \mathrm{~mm}$ \\
\hline Width of outer square ring patch $\left(W_{o}\right)$ & $47 \mathrm{~mm}$ \\
\hline Length of inner square ring patch $\left(L_{i}\right)$ & $41.7 \mathrm{~mm}$ \\
\hline Width of inner square ring patch $\left(W_{i}\right)$ & $41.7 \mathrm{~mm}$ \\
\hline Side Length of Hexagonal Patch & $9.11 \mathrm{~mm}$ \\
\hline Length of ground $(L)$ & $74.516 \mathrm{~mm}$ \\
\hline Width of ground $(W)$ & $84.5 \mathrm{~mm}$ \\
\hline Length of feed $\left(L_{f}\right)$ & $8.4 \mathrm{~mm}$ \\
\hline Width of feed $\left(W_{f}\right)$ & $6.11 \mathrm{~mm}$ \\
\hline Radius of the circle $(r)$ & $5.9 \mathrm{~mm}$ \\
\hline Substrate & FR4 \\
\hline Thickness & $3.2 \mathrm{~mm}$ \\
\hline Relative Permittivity & 4.4 \\
\hline
\end{tabular}

\section{Volume 6 Issue 12, December 2017}




\section{International Journal of Science and Research (IJSR) \\ ISSN (Online): 2319-7064}

Index Copernicus Value (2016): 79.57 | Impact Factor (2015): 6.391

Table 2: Specifications of dielectric superstrate

\begin{tabular}{|c|c|c|c|}
\hline $\begin{array}{c}\text { Superstrate } \\
\text { material }\end{array}$ & $\begin{array}{c}\text { Dielectric } \\
\text { Constant }\left(\varepsilon_{r}\right)\end{array}$ & $\begin{array}{c}\text { Loss Tangent } \\
(\text { Tan } \delta)\end{array}$ & $\begin{array}{c}\text { Thickness of } \\
\text { substrate }\end{array}$ \\
\hline FR-4 & $\varepsilon_{r 1}=4.4$ & 0.02 & $1.6 \mathrm{~mm}$ \\
\hline FR-4 & $\varepsilon_{r 2}=4.4$ & 0.02 & $3.2 \mathrm{~mm}$ \\
\hline
\end{tabular}

Table 2 shows the specifications for two layered superstrate structure overloaded on the patch. When the outer square ring and inner square ring are designed, the antenna resonates at $1.95 \mathrm{GHz}$. Then by designing four hexagonal patches for downlink frequency, the antenna resonates at $2.58 \mathrm{GHz}$. By introducing $\mathrm{V}$-slots in each hexagon, the antenna resonates at $1.98 \mathrm{GHz}$ and $2.16 \mathrm{GHz}$. By the superstrate structure the antenna resonates properly in the uplink $(1.99 \mathrm{GHz})$ and downlink $(2.18 \mathrm{GHz})$ frequency with less reflection coefficient.

\section{Results and Discussions}

The proposed antenna is simulated using Ansys HFSS which utilizes the 3D full-wave Finite Element Method (FEM) with adaptive meshing to compute the electrical behavior of highfrequency and high-speed components [8].

\subsection{Reflection Coefficient}

The reflection coefficient is a parameter that describes the ratio of the amplitude of the reflected wave to the incident wave. Figure 4 shows the simulation performance of the antenna in terms of S-Parameter $(\mathrm{dB}) \mathrm{Vs}$ the frequency (GHz).

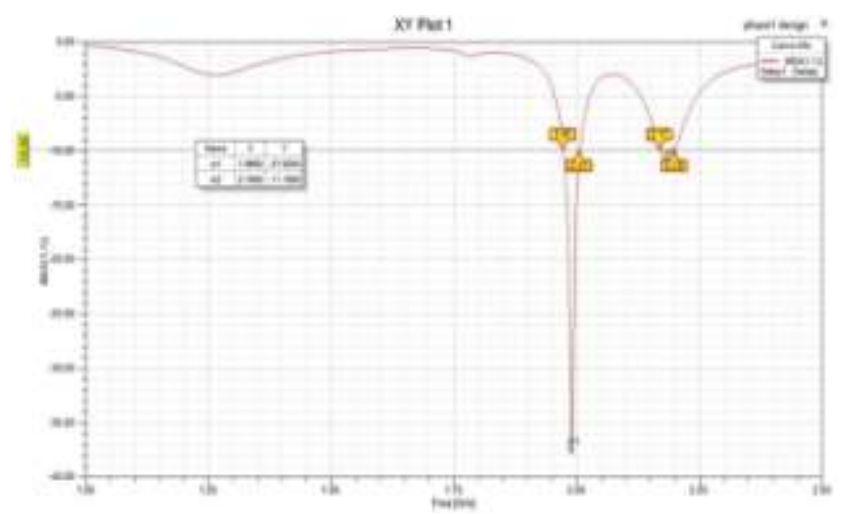

Figure 4: S-Parameter

From the figure 4 , it is noted that the simulated antenna has a good reflection coefficient of $-37.92 \mathrm{~dB}$ at the Uplink center frequency $1.99 \mathrm{GHz}$ and $-11.18 \mathrm{~dB}$ at the downlink center frequency $2.18 \mathrm{GHz}$. This frequency band corresponds to the S-band Mobile Satellite Services. The Bandwidth for uplink frequency is $40 \mathrm{MHz}$ and for downlink frequency is $30 \mathrm{MHz}$.

\subsection{Radiation Pattern}

It is the power radiated by an antenna as the function of direction far away from the antenna. The Figure 5 a) and b) shows the 2-D E-Plane and H-Plane radiation pattern of the antenna.
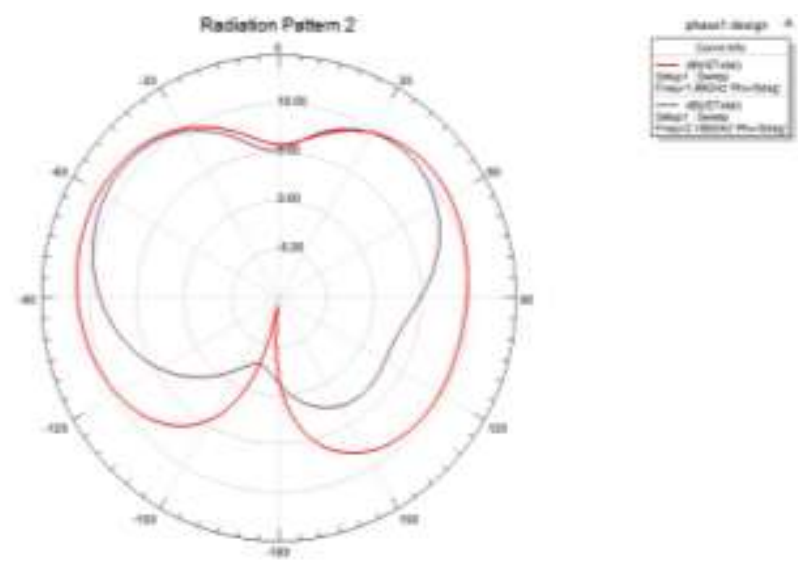

a) $\theta=0^{\circ}$ (E- Plane)
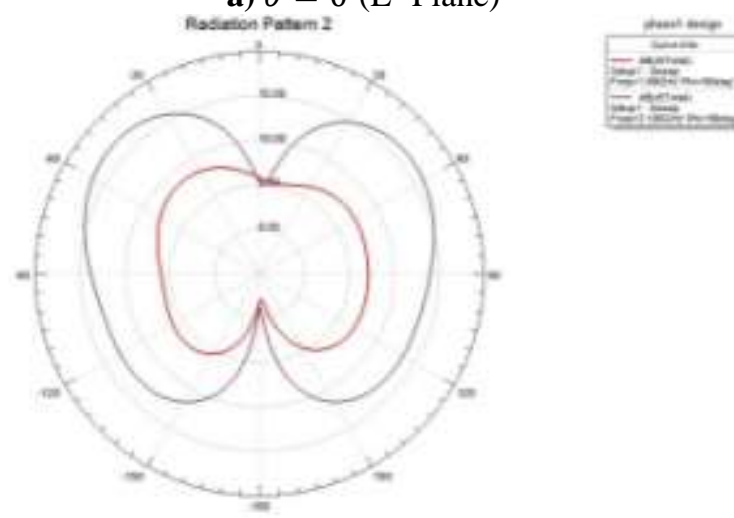

b) $\theta=90^{\circ}$ (H-Plane $)$

Figure 5: Radiation Pattern

The radiation pattern shows that the antenna has maximum main lobes and back lobes are completely suppressed. The antenna radiates with near Omni- directional coverage.

\subsection{VSWR}

VSWR abbreviation is Voltage Standing Wave Ratio and is also known as Standing Wave Ratio (SWR). It is a measure that describes how well the antenna is impedance matched to the transmission line. The VSWR range is less than 2.

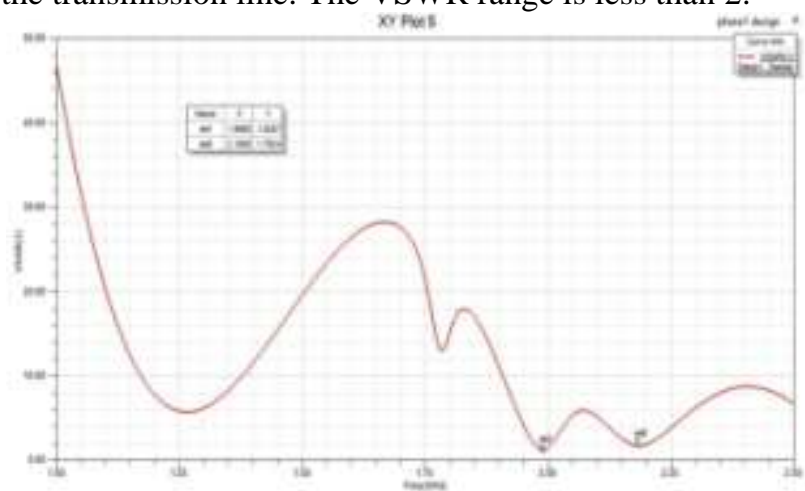

Figure 7: VSWR

From the above figure, it is noted that the proposed antenna design has good VSWR of 1.02 for uplink frequency and 1.76 for downlink frequency.

\subsection{Current Distribution}

The Figure 8 a) and b) shows the current distribution of the patch at $\varphi=0^{\circ}$ and $\varphi=90^{\circ}$ in the antenna. The current is

Volume 6 Issue 12, December 2017

\section{www.ijsr.net}

Licensed Under Creative Commons Attribution CC BY 


\section{International Journal of Science and Research (IJSR) \\ ISSN (Online): 2319-7064 \\ Index Copernicus Value (2016): 79.57 | Impact Factor (2015): 6.391}

distributed with respect to the excitation provided to the antenna.

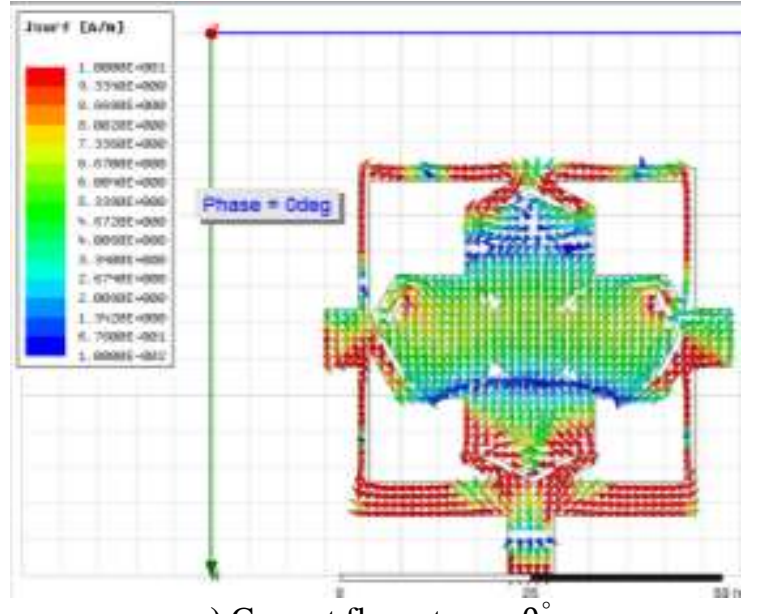

a) Current flow at $\varphi=0$

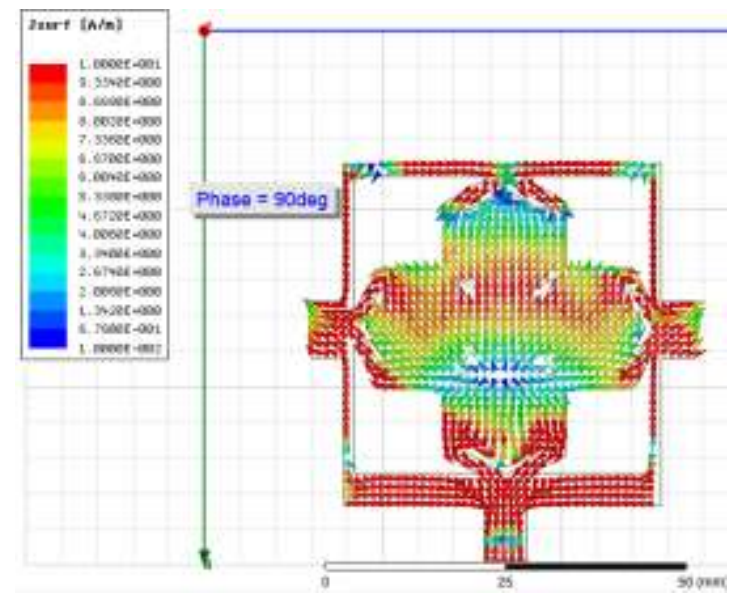

b) Current flow at $\varphi=90$

Figure 7: Current Distribution of designed Antenna

In the above figure the dark colour shows the maximum current distribution and light colour shows the minimum current distribution. The direction of current is indicated by arrow sign. In the patch maximum current is distributed in the edges of the patch especially along the V-slots.

\section{Conclusion}

The design of novel microstrip patch antenna covering the S-Band Mobile Satellite Services has been designed in Ansys HFSS software. A microstrip square ring patch along with four hexagonal patches with equal size is designed to achieve both uplink $(1.99 \mathrm{GHz})$ and downlink $(2.18 \mathrm{GHz})$ frequencies. Then four V-Shaped slots are introduced in each hexagonal patch to tune the antenna. Superstrate structure is incorporated to reduce the reflection coefficient. The proposed antenna has good reflection coefficient of $-37.92 \mathrm{~dB}$ at the uplink frequency and $-11.18 \mathrm{~dB}$ at the downlink frequency.

\section{References}

[1] Cesar Domínguez, Jose Padilla, Ferdinando Tiezzi, Rainer Wansch, Alexander Popugaev, "Multi-System Automotive Antenna For Mobile Satellite Communications Applications “, IEEE 6th Advanced
Satellite Multimedia Systems Conference (ASMS) and 12th Signal Processing for Space Communications Workshop (SPSC), 2012.

[2] Pushkar Lal Vijayvergiya, Rajib Kumar Panigrahi, "Single-layer single-patch dual band antenna for satellite applications", IET Microwave Antennas Propagation,2017 Vol. 11 Issue 5, pp. 664-669

[3] Jong-Min Park, Dae-Sub Oh, and Dong-Chul Park, "Coexistence of Mobile-Satellite Service System with Mobile Service System in Shared Frequency Bands", IEEE Transactions on Consumer Electronics, 2009,Vol. 55, No. 3, pp.1051-1052.

[4] Kouhalvandi, L., Paker, S., Yagci, H.B "Ku-band slotted rectangular patch array antenna design". 2015 23th IEEE Signal Processing and Communications Applications Conf. (SIU), pp. 447-450.

[5] Malisuwan, S., Sivaraks, J., Madan, N., et al. "Design of microstrip patch antenna for ku-band satellite communication applications", International Journal of Comput. Commun. Eng., 2014, 3, (6), p. 413.

[6] Basra, S., Goud, R.M., Singh, H, "Design of high gain wideband ku-band antenna using vertical slits and slots", 2014 Int. Conf. on IEEE Computational Intelligence and Communication Networks (CICN), 2014, pp. 55-59.

[7] C. A. Balanis, Antenna Theory - Analysis and Design (2nd Edition).

[8] ANSYS HFSS Electromagnetic simulator version16.

[9] S. H. S. Esfahlani, A. Tavakoli, and P. Dehkhoda, "A Compact Single-Layer Dual-Band Microstrip Antenna For Satellite Applications", IEEE Antennas And Wireless Propagation Letters, Vol. 10, 2011.

[10] M. Samsuzzaman , M. T. Islam, N . Misran, M.A. Mohd Ali , "Dual Band X Shape Microstrip Patch Antenna For Satellite Applications", ELSEVIER Publications, Procedia Technology 11(2013) pp. $1223-1228$.

\section{Author Profile}

Brinda received the B.E. degree in Electronics and Communication Engineering and M.E. degree in Digital Communication and Network Engineering. Currently she is pursuing her Ph.D. Her specialization field is Optical and Mobile Communication.

Nisha Flora Boby received the B.E. degree in Electronics and Communication Engineering from VV College of Engineering in the year 2016 and pursuing M.E. degree in Communication Systems from Mepco Schlenk Engineering College. Her work is focused on the antenna and design.

\section{Volume 6 Issue 12, December 2017}

